\title{
Patterns of Phytoindication Pollution of the Urban Environment the Maximum Width of the Leaves of the Silver Birch
}

\author{
Mazurkin P.M ${ }^{1}$., Kudryashova A.I ${ }^{2}$. \\ ${ }^{1}$ Dr. Sc., Prof., Volga State University of Technology, Yoshkar-Ola, Russia, \\ ${ }^{2}$ S. lec., Volga State University of Technology, Yoshkar-Ola, Russia, \\ kaf_po@mail.ru; Little-one7@yandex.ru
}

\begin{abstract}
We offer indicators in the form of groups of at least 10 accounting leaves growing during the growing season, selected and marked with a white thread of birch hanging from the prevailing winds. Was previously obtained regularities in the behavior of leaves in the vegetation period from the date of Bud wood to the subsidence of each account sheet. The method of measuring the width of birch leaves in the growing season is proposed. It was found that before reaching the maximum length, width, perimeter and area of leaves with at least 10 measurements per season, the patterns vary along the growing branch of the biotechnical law. Therefore, in the summer of 2018, measurements were carried out in the city of Yoshkar-Ola, starting from July 15 to the maximum width of the sheet, as the most convenient for measuring the parameter of the accounting sheet. It turned out that the maximum width of the sheet depends on the growing conditions of the tree. The aim is to identify the patterns of phytoindication by measuring the width of birch leaves hanging during the growing season near the maximum concentration of sulfur dioxide and carbon, the level of radioactive background at various points near the roads with the greatest pollution. The regularities of the influence of these types of pollution on the average maximum width and vegetation time from may 1, 2018 to the maximum width of the registration sheet are obtained. It turned out that even in an ecologically clean city (10th place in Russia), low concentrations are about 25 times less than MPC, have a strong influence on the growth and development of birch leaves. Initially, with an increase in the concentration of three chemicals at eight points of the urban environment have a beneficial effect on the vegetation of leaves. With further increase in concentration there is a strong inhibition of growth and development of leaves. The proposed method is recommended for school environmental groups.
\end{abstract}

Keywords: urban environment, pollution, birch leaves, vegetation, width, patterns

\section{Introduction}

In engineering ecology, the study of plant properties as indicators of environmental conditions was widely carried out [12]. According to [2], to assess the state of the urban environment it is necessary to study the interaction of factors. The environment receives a huge amount of pollutants [3].

Part of these substances uses the vegetation. In this case, the growing season becomes one of the important parameters, as the development of leaves is sensitive. It is especially promising to monitor the behavior of glandular hairs on the surface of birch leaves [13]. The leaves produce them throughout the growing season.

However, due to the complexity of the study of hairs, we took the leaves of trees under patents for inventions $2597643,2597645,2606189$ and 2615363 as the object of study. 
The main object of global and local environmental monitoring can be a birch with leaves without cutting them [4-6].Birch forests of the Northern hemisphere (Holarctic Kingdom by A. L. Takhtajyan [14]) occupy half of the world along the Arctic ocean. Models with wave components were obtained [4-6] on birch leaves growing in different ecological conditions. It is proved that air pollution dampens the mechanism of vibrational adaptation of leaves in the process of ontogenesis. With increasing air pollution, the date of maximum growth is reached earlier.

The article shows the laws of phytoindication by measuring the width of birch leaves hanging during the growing season near the maximum growth depending on the concentrations of sulfur dioxide and carbon, the level of radioactive background at various points near the roads with the greatest pollution.

\section{Materials and methods}

According to information [10] in Yoshkar-Ola in the rank of tree species birch was in third place due to the planting of the late seventies. In particular, they sought to embellish the Central streets of the city.

According to the actual content of sulfur dioxide and carbon dioxide, as well as the level of radioactive background on the streets of Yoshkar-Ola, it was noted that the concentration of sulfur dioxide in the atmospheric air of the city did not exceed the maximum permissible concentration $\left(0.5 \mathrm{mg} / \mathrm{m}^{3}\right)$. The concentration of carbon dioxide in different streets varied from 0.01 to $0.04 \%$ of the maximum permissible concentration. As shown by the results of studies, the radioactive background ranged from 0.08 to $0.15 \mathrm{mSv} / \mathrm{h}$, which is less than the limit of the natural background [1].

According to our invention patents $2597643,2597645,2606189$ and 2615363 obtained regularities in the behavior of leaves in the vegetation period from the date of Bud break, derivado the subsidence of each account sheet. It was found that before reaching the maximum length, width, perimeter and area of leaves with at least 10 measurements per season, the patterns vary along the growing branch of the biotechnical law.

Unlike patent 2606189 [11], measurements of sheet width (Fig. 1) it is more convenient and therefore it is proposed to use when comparing the places of growth of birch trees near roads with heavy traffic, taking into account the prevailing winds and sources of pollution in different environmental conditions of the city. 


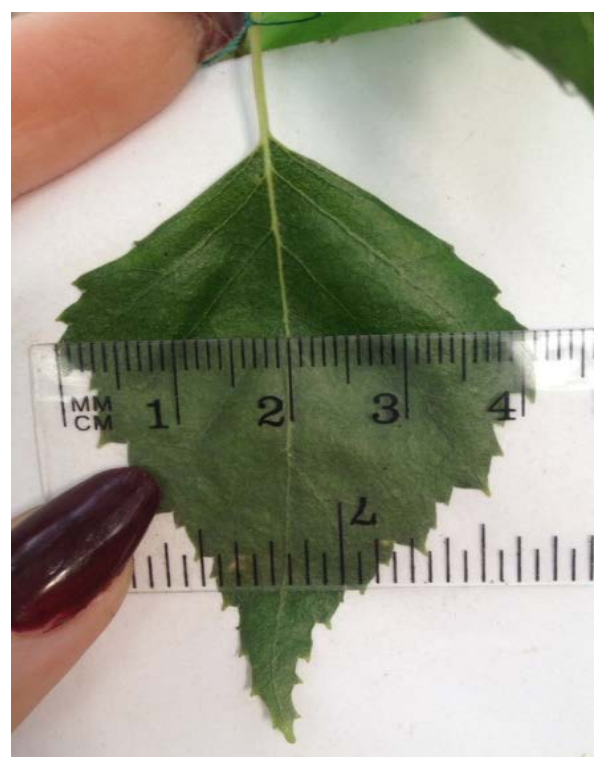

Fig 1. Measure the width of the sheet

On a sheet put a transparent ruler so that the line of a mark of some centimeter was located with the axis of the longitudinal vein of the sheet. In figure 1, the vein coincided with the line $2 \mathrm{~cm}$. Then, a sheet with a ruler is photographed with a digital camera with the function of storing photographs. On the computer, the photo sheet is cut, then increased to count to A4.

For multiple measurements, each registration sheet was marked with a white thread with a tag with a number attached to the petiole at the base of the sheet.

The experiments were carried out in the ecologically clean city of Yoshkar-Ola (10th place in Russia) [12] at various points near the roads with the greatest pollution.

Table 1 shows a fragment of experimental data with birch leaves.

Table 1. A comparison of the contamination of the urban environment with the maximum width of the leaves of the birch in time of the vegetation period

\begin{tabular}{|l|c|c|c|c|c|}
\hline \multirow{2}{*}{$\begin{array}{c}\text { Place of growth } \\
\text { birch accounting }\end{array}$} & $\begin{array}{c}\mathrm{SO}_{2}, \\
10^{-2} \mathrm{mg} / \mathrm{m}^{3}\end{array}$ & $\begin{array}{c}\mathrm{CO}_{2}, \\
10^{-2} \mathrm{mg} / \mathrm{m}^{3}\end{array}$ & $\begin{array}{c}\text { Radioactive } \\
\text { background } \\
R_{f}, \mathrm{mcZv} / \mathrm{h}\end{array}$ & $\begin{array}{c}\text { Time } \\
\text { vegetations, } \\
\tau, \text { day }\end{array}$ & $\begin{array}{c}\text { Maximum } \\
\text { sheet width, } \\
\bar{b}_{\text {max }}, \mathrm{mm}\end{array}$ \\
\hline Lebedev Street & 1 & 1 & 0.08 & 110 & 45.92 \\
\hline Voskresensky prospect & 2 & 2 & 0.10 & 110 & 48.66 \\
\hline Street Eshkinina & 4 & 3 & 0.10 & 92 & 39.77 \\
\hline Lenin avenue & 3 & 3 & 0.12 & 99 & 40.11 \\
\hline Chawain Boulevard & 2 & 2 & 0.12 & 106 & 44.71 \\
\hline Panfilov Street & 3 & 3 & 0.14 & 103 & 39.56 \\
\hline Karl Marx Street & 3 & 4 & 0.16 & 99 & 44.39 \\
\hline Builders Street & 5 & 4 & 0.16 & 103 & 42.25 \\
\hline
\end{tabular}

It adopted the following symbols:

$\mathrm{SO}_{2}$ - changing the concentration of sulfur dioxide on the streets, $\mathrm{mg} / \mathrm{m}^{3}$;

$\mathrm{CO}_{2}$ - changing the concentration of carbon dioxide on the streets, $\mathrm{mg} / \mathrm{m}^{3}$; 
$R_{f}$ - changing the background radiation on the streets of Yoshkar-Ola, mcZv/h (equivalent dose within in microsievert per hour);

$\tau$ - time vegetation from Bud break in 2018 from may 1 to the maximum width, day;

$\bar{b}_{\max }-$ maximum leaf width during the growing season, $\mathrm{mm}$.

For the convenience of modeling sulfur dioxide and carbon are multiplied by 100 , and in fact, for example, on Lebedev street, equal to $0.01 \mathrm{mg} / \mathrm{m}^{3}$.

The trend is formed when the period of oscillation tends to infinity. [7-9]. All models in this article were identified by the two-term formula

$$
y=\operatorname{aexp}\left(-b x^{c}\right)+d x^{e} \exp \left(-f x^{g}\right)
$$

where $y$-the dependent measure, $x$-influencing variable, $a-g$-model parameters (1) identified in the software environment CurveExpert-1.40.

The first member is modified by law Laplassa, and the second - biotech law [7].

\section{Results}

In the summer of 2018, measurements were carried out in the city of Yoshkar-Ola, starting from July 15 to the maximum growth of the sheet in width. It turned out that the maximum width of the leaf depends on the growing conditions of the tree and varies from the beginning of vegetation on may 1 for $92-110$ days.

The regularities of the influence of sulfur dioxide and carbon dioxide concentrations, the level of radioactive background on the average maximum width and vegetation time from may 1, 2018 to the maximum width of the registration sheet are obtained.

Figure 2 shows graphs of the effect of sulfur dioxide $\mathrm{SO}_{2} \rightarrow \tau$ concentration on the growing season of birch leaves and $\mathrm{SO}_{2} \rightarrow \bar{b}_{\max }$ the maximum width of the leaf.
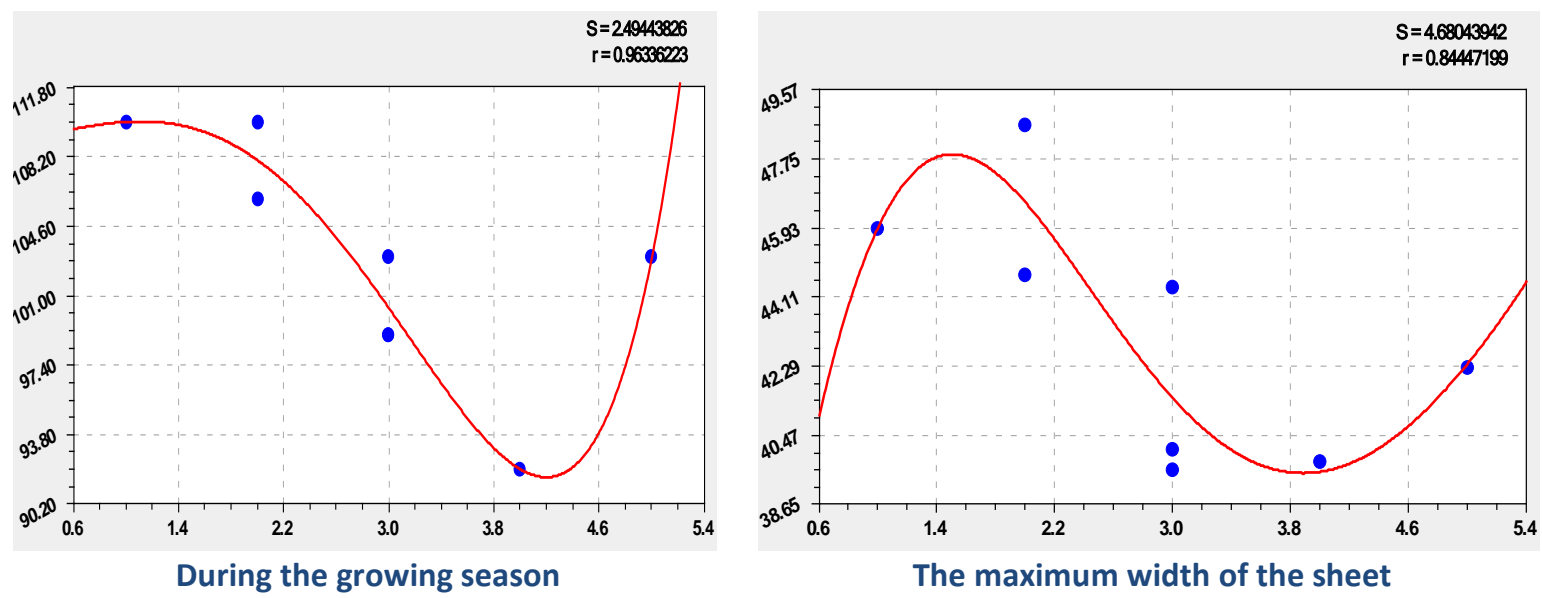

Fig. 2. Graph the influence of the concentration of sulphur dioxide

The effect of the concentration of sulphur dioxide during the growing season

$$
\tau=109,07953 \exp \left(0,36575 \mathrm{SO}_{2}{ }^{2,11956}\right)-3,14298 \mathrm{SO}_{2}{ }^{2,66043} .
$$

The effect of the concentration of sulphur dioxide at the maximum width of the sheet 


$$
\overline{\mathrm{b}}_{\max }=0,08466 \exp \left(6,32267 \mathrm{SO}_{2}^{4,26871}\right)-5,79832 \cdot 10^{7} \mathrm{SO}_{2}^{9,53251} \exp \left(-17,69806 \mathrm{SO}_{2}^{0.323017}\right)(3)
$$

Figure 3 shows graphs of the effect of carbon dioxide $\mathrm{CO}_{2} \rightarrow \tau$ concentration on leaf vegetation and $\mathrm{CO}_{2}$ $\rightarrow \bar{b}_{\max }$ on the maximum leaf width.

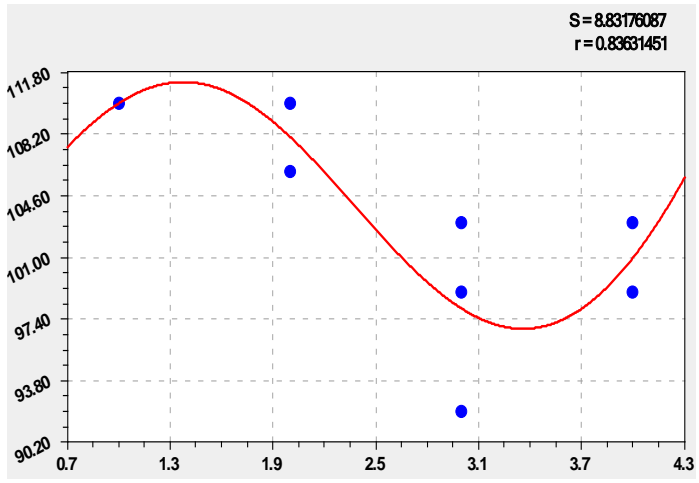

During the growing season

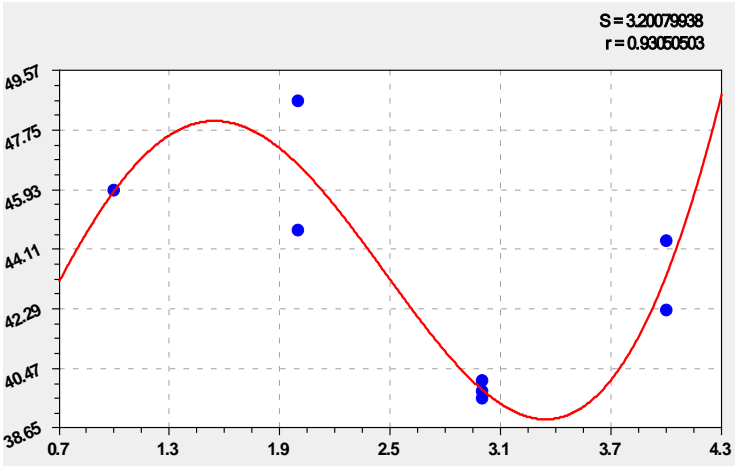

The maximum width of the sheet

Fig. 3. Graph of influence of carbon dioxide concentration

Influence of carbon dioxide concentration on the growing season

$$
\tau=97,54959 \exp \left(0,13322 \mathrm{CO}_{2}{ }^{0,80153}\right)-2,11224 \mathrm{CO}_{2}{ }^{4,35819} \exp \left(-0,37548 \mathrm{CO}_{2}{ }^{1,49377}\right) .
$$

Effect of carbon dioxide concentration on maximum width

$$
\overline{\mathrm{b}}_{\max }=35,16704 \exp \left(0,310709 \mathrm{CO}_{2}^{0,99992}\right)-4,48249 \mathrm{C}_{2}{ }^{4,30896} \exp \left(-0,77667 \mathrm{CO}_{2}^{1,00081}\right)
$$

With an increase in the concentration of sulfur dioxide and carbon modified Laplace's law grows, and according to the exponential law with a negative sign is reduced, the growing season is shifted to the beginning of ontogenesis. The conditions for the growth and development of the list of the best was the street Lebedev, and the worst - Eshkinina.

Figure 4 shows graphs of influence of radioactive background $R_{f} \rightarrow \tau$ at the time of the growing season the leaves and $R_{f} \rightarrow \bar{b}_{\max }$ on the maximum width of the sheet.
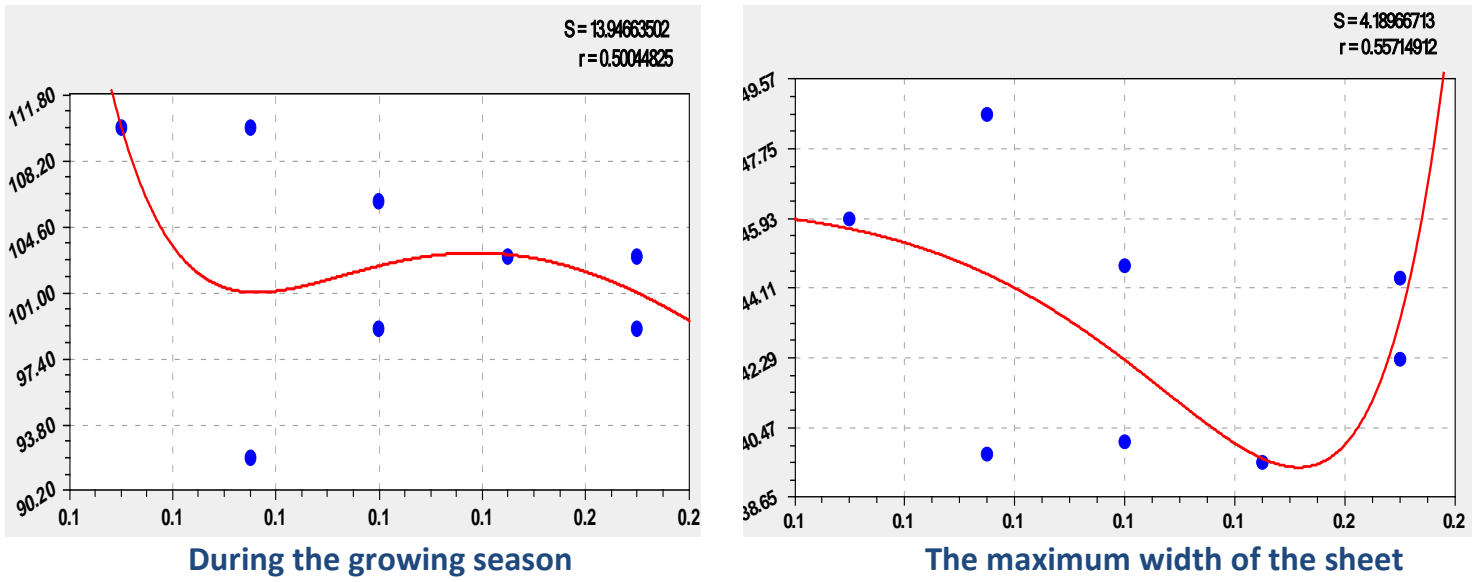

Fig. 4. A graph of the influence of radioactive background

The effect of background radiation during the growing season

$$
\tau=1,54079 \cdot 10^{5} \exp \left(-11,05799 \mathrm{R}_{\mathrm{f}}{ }^{0,37244}\right)-1.06089 \cdot 10^{5} \mathrm{R}_{\mathrm{f}}^{0,1994} \exp \left(-13,28765 \mathrm{R}_{\mathrm{f}}{ }^{0,52879}\right)
$$


The effect of background radiation on the maximum sheet width

$$
\overline{\mathrm{b}}_{\max }=46,27237 \exp \left(72695,278 \mathrm{R}_{\mathrm{f}}^{6,35945}\right)-1.0415106 \mathrm{R}_{\mathrm{f}}^{5,50019}
$$

With the further growth of the radioactive background, the conditions of leaf growth worsen, have a large spread, the patterns are obtained with very small correlation coefficients, so additional research is needed.

\section{Conclusions}

The method of measuring the width of the leaves in the growing season is recommended for school environmental circles to observe the growth and development of tree leaves in urban parks, alleys, roadsides.

Measurements of the width of birch leaves in the growing season, selected and marked with a white thread from the prevailing winds, it is possible to identify patterns of phyto-indication depending on the concentrations of sulfur dioxide and carbon, as well as the level of radioactive background at various points near roads.

Even in the ecologically clean city of Yoshkar-Ola small concentrations of pollutants are about 25 times less than the maximum, but have a strong impact on the growth and development of birch leaves. Initially, with an increase in the concentration of three chemicals at eight points of the urban environment to a certain level have a beneficial effect on the vegetation of leaves. With further increase in concentration there is a strong oppression and inhibition of growth and development of leaves.

\section{REFERENCES}

[1] Voskresenskaya O. L., Voskresensky V. S., Starikova E. A. Analysis of the ecological situation on the streets of Yoshkar-Ola on the content of sulfur oxides, carbon and the level of radioactive background. Modern problems of medicine and natural Sciences: collection of articles of the all-Russian scientific conference. Issue. 7, Yoshkar-Ola, 23-27 April 2018 / Mar. state UN-T. - Yoshkar-Ola, 2018. P. 402-405.

[2] Kirillov S. N., Polovinkin Y. S. an Integrated geoecological assessment of the territory of the city of Volgograd. Vestn. ]. state University. Ser. 3, Ekon.Ekol. 2011. № 1 (18) 239. Date of access 29.10.2016.

[3] Kochurov B. I. ecodiagnostics and balanced development: proc. manual / B. I. Kochurov. Moscow: Smolensk: Magenta, 2003. 384 p.

[4] Kudryashova A. I., Regularities in the growth dynamics of tree leaves // Mater. II international scientific and practical conference "Socio-economic development of the territory». Penza: PGAS, 2015. P. 124-133.

[5] Mazurkin P.M., Kudryashova A. I., Patterns of ontogenesis of tree leaves. Dynamics of growth of the leaves of lime and birch in pure and polluted by automobile exhaust in the urban environment. Germany: LABLAMBERTAcademicPublishing, 2015. 1003. 
[6] Mazurkin P. M., Kudryashova A. I., Dynamics of the ontogeny of the leaves of the tree. Yoshkar-Ola: PSTU, 2015. 172 p.

[7] Mazurkin P. M., Invariants of the Hilbert Transform for 23-Hilbert Problem,Advances in Sciences and Humanities. Vol. 1, No. 1, 2015, pp. 1-12. doi:10.11648/j.ash.20150101.11.

[8] Mazurkin P. M., Method of identification. International Multidisciplinary Scientific GeoConference, Geology and Mining Ecology Management, SGEM, 2014, 1(6), pp. 427-434. https://www.scopus.com/inward/record.uri?eid=2-s2.0$\underline{84946541076 \& \text { partnerlD }=40 \& m d 5=72 a 3 f c c e 31 b 20 f 2 e 63 e 4 f 23 e 9 a 8 a 40 e 3}$

[9] Mazurkin P. M., Wavelet Analysis Statistical Data. Advances in Sciences and Humanities.Vol. 1, No. 2, 2015, pp. 30-44. doi: 10.11648/j.ash.20150102.11.

[10] Maryshev V. Top 10 most common tree species of Yoshkar-Ola. URL: http://www.marpravda.ru/news/gorod/derevya-yoshkar-oly-ot-lipy-do-duba/ (accessed 25.11.2016).

[11] Pat. 2606189 Russian Federation, IPC G 01 D21 / 00(2006.01). Method factor analysis of the ontogeny of the account tree leaves / Mazurkin, P. M., Kudryashova A. I.; applicant and patentable.Mazurkin, P. M. No. 2015112149; Appl. 03.04.2015; publ. 10.01.2017. Bul. No. 1.

[12] The concept of sustainable development. URL: http://green-agency.ru/ponyatie-istoriya-isfery-ustojchivogo-razvitiya/. Date of application 28.02.2015).

[13] The cleanest cities of Russia 2018-2019. URL: http://top10a.ru/10-samyx-chistyx-gorodovrossii-v-2018-godu.html. Date of treatment 08.04.2019.

[14] Takhtajan A.L. Floristic regions of the world.The Regents of the University of California $1986.523 \mathrm{p}$.

[15] Thitz P. et.al. Production of glandular trichomes responds to water stress and temperature in silver birch (Betulapendula) leaves/ Canadian Journal of Forest Research, 2017, 47(8): 1075-1081, https://doi.org/10.1139/cjfr-2017-0036. 